\title{
O registro como forma de proteção do patrimônio cultural imaterial
}

Mário Ferreira de Pragmácio Telles*

\section{Resumo}

Analisa-se, neste artigo, o instituto do registro, visando diagnosticar a eficácia desse instrumento de proteção do patrimônio cultural imaterial.

Palavras-chave: Direitos culturais. Patrimônio cultural imaterial. Registro.

\section{The registry as a sort of protection of the intangible cultural heritage}

\begin{abstract}
This paper analyses the institute of the registry and also tries to diagnose the efficacy of this instrument of protection of the intangible cultural heritage.
\end{abstract}

Key-words: Cultural rights. Intangible cultural heritage. Registry.

\section{Introdução}

O estudo dos direitos culturais - já inserido por alguns entre os "novos direitos" - está em ascensão. Contudo, as pesquisas realizadas sobre o assunto, apesar de poucas, ainda não criaram consciência de sua unidade, sendo os trabalhos, ainda, bastante esparsos nas diversas áreas do Direito.

A doutrina jurídica sobre o assunto concentra-se, recorrente e insistentemente, em institutos como o tombamento e a desapropriação, revelando, assim, uma ausência de ousadia ou, até mesmo, de compromisso com o conhecimento. Portanto, a presente pesquisa possui, também, o escopo de contribuir para o preenchimento desta lacuna, apresentando como tema: o registro como forma de proteção do patrimônio cultural imaterial. 
O presente trabalho foi estruturado em três capítulos: o primeiro pretende localizar o tema da pesquisa dentro das Ciências Jurídicas; o segundo trata do registro, oferecendo uma análise jurídica desse instituto e do Decreto que o regulamentou; o último capítulo tece comentários acerca do procedimento de registro descrito no referido Decreto e na práxis administrativa, auferindo, ainda, exemplo de todos os bens imateriais que são registrados como patrimônio cultural brasileiro.

\section{Patrimônio cultural}

Neste capítulo faz-se, primeiramente, uma necessária iniciação à doutrina jurídica dos Direitos Culturais. A seguir, aprofunda-se a pesquisa sobre o conceito e a evolução do patrimônio cultural, abordando suas dimensões material e imaterial. Por fim, apresentam-se as formas de proteção desse patrimônio, previstas no $\S 1^{\circ} \mathrm{do}$ art. 216 da Constituição Federal de 1988, dentre as quais encontra-se o registro, objeto de estudo do presente trabalho.

\subsection{Introdução aos direitos culturais}

Antes de adentrar ao estudo do patrimônio cultural e suas formas de proteção, é necessário entender, inicialmente, a localização desse tema dentro da Ciência Jurídica, bem como saber qual é a sua natureza jurídica. Sabe-se que o patrimônio cultural faz parte dos chamados direitos culturais, mas o que são tais direitos?

A expressão direitos culturais surgiu pela primeira vez na história constitucional brasileira com o advento do artigo 215 da Constituição Federal de 1988 (1). Contudo, a existência de tais direitos remonta às Constituições anteriores de forma aleatória e dispersa, referindo-se, basicamente, às belas-artes, ao beletrismo e ao patrimônio edificado (CUNHA FILHO, p.12) (2).

A doutrina jurídica cultural (3) vem buscando construir um conceito de direitos culturais, no intuito de preencher a lacuna constitucional e aprofundar os estudos nessa nova seara do Direito.

A ambientalista Lúcia Reisewitz constata a imprecisão da Carta Política para uma definição dos direitos culturais prevista no artigo 215 , in verbis: 
"Não cuidou, no entanto, a Lei Maior de trazer uma definição explícita sobre o exato significado da expressão direitos culturais, questão que deve encontrar solução através de uma interpretação sistemática da Constituição, em conjunto com a análise da legislação infraconstitucional sobre o tema." (REISEWITZ, 2004, p.78, grifo do autor).

Na visão desta autora (REISEWITZ, 2004, p.77), "os direitos culturais englobam todos aqueles direitos que implicam em participação na vida cultural, que viabilizam o contato da população com as fontes da cultura e com a natureza [...]". Apesar da generalidade de tal sentença, principalmente na árdua identificação do que vem a ser vida cultural, tal definição já é um avanço para se chegar a um conceito de direitos culturais.

José Afonso da Silva, apesar de não fornecer um conceito do que sejam os direitos culturais, explicita quais são estes direitos reconhecidos na Constituição Federal de 1988:

"(a) liberdade de expressão da atividade intelectual, artística, científica; (b) direito de criação cultural, compreendidas as criações artísticas, científicas e tecnológicas; (c) direito de acesso às fontes de da cultura nacional; (d) direito de difusão das manifestações culturais; (e) direito de proteção às manifestações das culturas populares, indígenas e afro-brasileiras e de outros grupos participantes do processo civilizatório nacional; (f) direito-dever estatal de formação do patrimônio cultural brasileiro e de proteção dos bens de cultura." (SILVA, 2001, p.51-52, grifo nosso).

Com essa exemplificação dos direitos culturais, percebe-se que a formação do patrimônio cultural brasileiro - e, conseqüentemente, as formas de proteção desse patrimônio, dentre as quais se inclui o registro - é parte integrante dos direitos culturais.

Francisco Humberto Cunha Filho, não obstante ser o primeiro doutrinador a fornecer uma definição de direitos culturais, possui também a melhor conceituação dos ditos direitos, in verbis:

"Direitos Culturais são aqueles afetos às artes, à memória coletiva e ao repasse de saberes, que asseguram a seus titulares o conhecimento e uso do passado, interferência ativa no 
presente e possibilidade de previsão e decisão de opções referente ao futuro, visando sempre à dignidade da pessoa humana." (CUNHA FILHO, 2000, p.34).

Adota-se neste trabalho a definição de direitos culturais criada pioneiramente por Humberto Cunha, uma vez que atende a necessidade científica básica de identificação clara do objeto para, só então, elaborar um estudo mais aprofundado sobre este.

\subsubsection{Direitos culturais como um ramo autônomo do Direito}

Os direitos culturais também podem ser entendidos como um ramo autônomo do Direito. Esta é a posição que Humberto Cunha Filho vem sistematizando ao longo de seus trabalhos, considerando que todos os direitos culturais que estão espalhados nas diversas áreas do Direito (4) possuem principiologia peculiar e um ponto em comum: referência à tríade artes - memória coletiva - repasse de saberes.

Lúcia Reisewitz (2004, p.76), ao lado de Humberto Cunha Filho, assume uma posição de vanguarda ao afirmar que "os direitos culturais brasileiros e o direito ambiental convergem para um ponto comum". Tal equiparação da ambientalista prenuncia, mesmo que indiretamente, a existência de um novel ramo do Direito, a saber, os direitos culturais.

Reisewitz também propõe uma interdisciplinaridade entre direito ambiental e direito cultural, mormente no que se refere ao patrimônio cultural, descentralizando, dessa forma, os estudos jurídicos desse tema, os quais estão concentrados, em grande parte, no direito ambiental:

“A preocupação do Estado e, portanto, do direito, com a cultura deve perpassar três fundamentais aspectos: o fomento e incentivo das atividades culturais, a divulgação da cultura nacional e, finalmente, sua preservação. É esta última manifestação da política cultural que é também objeto do direito ambiental, pois o direito à preservação do patrimônio cultural é justamente o direito à preservação de um ambiente: o cultural, que é meio para garantia da qualidade de vida humana. Portanto, a preservação do patrimônio cultural é, a um só tempo, direito ambiental e direito cultural (sic)." (REISEWITZ, 2004, p.7677 , grifo nosso). 
José Afonso da Silva, por outro lado, não reconhece o direito cultural como um ramo autônomo do Direito. Assim se posiciona este constitucionalista:

\footnotetext{
"O conjunto de normas jurídicas que disciplinam as relações de cultura forma a ordem jurídica da cultura.

Esse conjunto de todas as normas jurídicas, constitucionais ou ordinárias, é que constitui o direito objetivo da cultura, e quando se fala em direito da cultura se está se referindo ao direito objetivo da cultura, ao conjunto de normas sobre cultura." (SILVA, 2001, p.47, grifo do autor).
}

Percebe-se que José Afonso da Silva (2001) não aufere valores qualitativos a esse conjunto de normas relativas à cultura, no sentido de atribuir-lhes uma autonomia unificadora consubstancial, sendo, na visão deste autor, apenas uma organização (ordenação) de normas culturais sob a égide do direito constitucional.

Este trabalho, portanto, adere ao pensamento moderno de Humberto Cunha Filho (2000) e Lúcia Reisewitz (2004), pretendendo solidificar uma doutrina jurídica acerca dos direitos culturais.

\subsection{Patrimônio cultural na Constituição Federal de 1988}

Em consonância com o conceito moderno de patrimônio cultural, o qual foi influenciado principalmente pelas cartas internacionais sobre o assunto (5), bem como pelos debates ocorridos na comunidade cultural brasileira nas décadas de setenta e oitenta do século passado (6), a instalação da Constituinte Brasileira, segundo Luciano Lima Rodrigues, teve um papel fundamental à formação do atual conceito brasileiro de patrimônio cultural:

"A instalação da Constituinte Brasileira no final dos anos 80 foi também um marco considerável na construção do atual conceito de patrimônio cultural, uma vez que as forças dos partidos de esquerda, dos grupos intelectuais e dos órgãos de cultura juntaram-se para construir um conceito de patrimônio cultural de conteúdo mais dinâmico, mais vivo, mais popular e, acima de tudo, que favorecesse o exercício da cidadania, processo que vinha sendo construído desde os anos 70." (RODRIGUES, 2006, p.11). 
Nesse contexto, surgiu o artigo 216 da Constituição Federal de 1988, o qual estabeleceu um largo conceito de patrimônio cultural, in verbis:

\begin{abstract}
"Constituem patrimônio cultural brasileiro os bens de natureza material e imaterial, tomados individualmente ou em conjunto, portadores de referência à identidade, à ação, à memória dos diferentes grupos formadores da sociedade brasileira, nos quais se incluem [...]."
\end{abstract}

Reisewitz aborda com propriedade o alargamento conceitual que o patrimônio cultural recebeu com o advento do mencionado dispositivo constitucional:

\begin{abstract}
"Com a Constituição Federal de 1988, o conceito de patrimônio cultural sofreu sua mais significativa ampliação no que diz respeito à materialidade ou imaterialidade dos bem culturais tutelados, indo de encontro à própria concepção atual que se tem de cultura e ao contrário do Decreto-lei n. 25/1937 e da Convenção Relativa à Proteção do Patrimônio Cultural e Natural Mundial, que prestigiaram apenas os bens materiais." (REISEWITZ, 2004, p.99).
\end{abstract}

Dessa forma, o patrimônio cultural passou a ser compreendido não só pelo seu aspecto tangível (corpóreo), mas, sobretudo, levando-se em conta a existência do patrimônio imaterial (incorpóreo). Na verdade, essa divisão entre patrimônio cultural material e patrimônio cultural imaterial será adotada neste trabalho como um recurso didático, uma vez que ambos

“[...] não aparecem mais como duas áreas separadas, mas como um conjunto único e coerente de manifestações múltiplas, complexas e profundamente interdependentes dos inúmeros componentes da cultura de um grupo social." (LÉVI-STRAUSS, 2001, p.24).

\title{
2.2.1 Patrimônio cultural material
}

A dimensão material é, sem dúvida, a parte mais notória do patrimônio cultural. Seria, fazendo uma analogia com o fenômeno humano, o equivalente ao corpo, enquanto que a dimensão imaterial do patrimônio seria a alma de uma comunidade.

O conceito de monumentabilidade e autenticidade, até meados do século passado, eram os alicerces da visão "pedra e cal" do patrimônio. Este ainda vige, contudo aquele foi substituído, principalmente após a Carta de Veneza, pelo significado 
cultural do bem, fomentando a valorização dos bens de pequeno porte físico que tinham seus reconhecimentos ofuscados pelas construções colossais. Portanto, patrimônio cultural material, atualmente, é muito mais que grandes prédios; é, principalmente, o significado que um bem carrega.

Tanto podem existir bens materiais móveis como imóveis. São exemplos de patrimônio cultural material: os Arcos da Lapa, no Rio de Janeiro; as Jarras de Louça de Cachoeira, Bahia; o Passeio Público, na capital cearense; e as dezesseis imagens, representando a morte de Nossa Senhora, em Canguaretama, Rio Grande do Norte (7).

\subsubsection{Patrimônio cultural imaterial}

A Convenção para a Salvaguarda do Patrimônio Cultural Imaterial (on line), aprovada pela Unesco em 17 de outubro de 2003, assim define patrimônio cultural imaterial:

\footnotetext{
“Entende-se por 'patrimônio cultural imaterial' as práticas, representações, expressões, conhecimentos e técnicas - junto com os instrumentos, objetos, artefatos e lugares que the são associados - que as comunidades, os grupos e, em alguns casos, os indivíduos reconhecem como parte integrante de seu patrimônio cultural. Este patrimônio cultural imaterial, que se transmite de geração em geração, é constantemente recriado pelas comunidades e grupos em função de seu ambiente, de sua interação com a natureza e de sua história, gerando um sentimento de identidade e continuidade, contribuindo assim para promover o respeito à diversidade cultural e à criatividade humana." (UNESCO, 2006).
}

A dimensão imaterial do patrimônio possui características diferenciadas de sua versão material. Destacam-se a dinamização do bem imaterial - uma vez que o patrimônio imaterial sofre constante mutação em virtude dos elementos inovadores que são incorporados em seu aspecto - e a paradoxalmente mais visível que é a intangibilidade, ou seja, a natureza incorpórea do bem - apesar de se manifestar, quase sempre, materialmente.

Cunha descreve os elementos componentes e formadores do patrimônio imaterial, auferindo exemplos bastante ilustrativos: 
"As formas de expressão, os modos de criar, fazer e viver, as criações científicas, artísticas e tecnológicas e demais atividades possuidoras de referência à identidade, à ação, à memória dos diferentes grupos formadores da sociedade brasileira compõem o patrimônio imaterial. Assim, nossas língua e danças, canções, música, celebrações, nosso artesanato, literatura, artes plásticas, cinema, televisão, humor, cozinha e o nosso próprio modo de ser e interpretar a vida formam o patrimônio imaterial." (CUNHA, 2004, p.119).

O presente trabalho pretender elaborar um estudo acerca das formas de proteção dessa dimensão intangível do patrimônio cultural, tão rica no Brasil.

\subsubsection{Formas de proteção do patrimônio cultural imaterial}

$O \S 1^{\circ}$ do artigo 216 da Constituição Federal descreve quais são os instrumentos de proteção do patrimônio cultural brasileiro, ipsis litteris:

\footnotetext{
"O Poder Público, com a colaboração da comunidade, promoverá e protegerá o patrimônio cultural brasileiro, por meio de inventários, registros, vigilância, tombamento e desapropriação, e de outras formas de acautelamento e preservação." (grifo nosso).
}

Registros, inventários (8) e vigilância constituem, segundo o mandamento constitucional, as formas de proteção do patrimônio cultural imaterial, sendo que estes últimos também são aplicáveis ao patrimônio cultural material.

O mencionado dispositivo não se reveste de auto-executoriedade, sendo, assim, necessária sua regulamentação através de legislação infraconstitucional. Contudo, de todos os instrumentos de proteção elencados no artigo 216 da Carta Política, somente o registro foi regulamentado, através do Decreto 3551 , de 4 de agosto de 2000 (9).

É fato que a doutrina especializada concentrou quase que a totalidade de seus estudos na investigação do instituto do tombamento. São quase inexistentes os trabalhos jurídicos acerca do inventário, desapropriação, vigilância e outros instrumentos de acautelamento e preservação do patrimônio cultural previstos na Lei das Leis. 
No intuito de reverter tal constatação, este trabalho estudará o registro, principalmente por seu instrumento normativo regulamentador, o Decreto 3551/2000, o que será feito, oportunamente, no capítulo seguinte.

\section{Registro}

Neste capítulo, analisa-se mais especificamente o instituto do registro, o qual está previsto no artigo $216, \S 1^{\circ}$ da Constituição Federal de 1988 , e foi regulamentado pelo Decreto 3551 de 4 de agosto de 2000.

\subsection{Histórico da criação do decreto que regulamentou o registro}

Três instrumentos influenciaram sobremaneira a criação do Decreto 3551/2000. O primeiro, de cunho jurídico-internacional, foi a Recomendação sobre a Salvaguarda da Cultura Tradicional e Popular da Unesco; o segundo, de direito interno, o advento do art. 216 da Constituição de 1988; e o terceiro, de caráter acadêmico, a Carta de Fortaleza.

Como já foi visto no capítulo anterior, o conceito de patrimônio cultural inserto na Convenção da Unesco sobre a Proteção do Patrimônio Mundial, Cultural e Natural de 1972 é essencialmente material. Em face disso, alguns países que possuem um vasto e rico patrimônio imaterial, tendo à frente a Bolívia, requisitaram à Unesco maiores estudos no intuito de criar instrumentos jurídicos para salvaguardar, principalmente, as manifestações da cultura popular e tradicional destes países, incluindo-as também como patrimônio da humanidade (BRASIL, 2000, p.94).

Tais pesquisas culminaram na Recomendação sobre a Salvaguarda da Cultura Tradicional e Popular, criada na 25a Conferência Geral da Unesco, realizada em Paris, em 15 de novembro de 1989, sendo tal documento o marco inicial à proteção do patrimônio cultural imaterial no mundo ocidental (10). No subitem "b" da segunda parte desse documento, intitulada Identificação da Cultura Tradicional e Popular, recomenda-se in verbis:

"b) criar sistemas de identificação e registro (cópia, indexação, transcrição) ou melhorar os já existentes por meio de manuais, guias para recompilação, catálogos-modelo etc., em 
vista da necessidade de coordenar os sistemas de classificação utilizados pelas diversas instituições." (RECOMENDAÇÃO, 2000, grifo nosso).

Vê-se, portanto, que esse registro disposto na Recomendação sobre a Salvaguarda da Cultura Tradicional e Popular de 1989 possui semelhança e influenciou o registro contido no decreto 3551/2000, principalmente no que concerne ao caráter identificador de bens imateriais que este possui.

Assim, já se buscavam na sociedade internacional meios de se proteger o patrimônio cultural imaterial, forçando a Unesco a assumir um papel fundamental de sintetizador de experiências locais e incentivando os estados-membros a aprofundarem seus próprios instrumentos de proteção.

No Brasil, os debates acerca da importância da proteção do patrimônio cultural imaterial ganharam força com o visionário anteprojeto de Mário de Andrade, cujo teor dedicava importância às manifestações e expressões populares. Apesar de ter sido elaborada em 1936, as idéias contidas em tal proposta de lei só foram retomadas na década de 1970, deixando uma grande lacuna temporal e atrasando significativamente as ações de proteção ao patrimônio cultural.

Os debates ocorridos nas décadas de setenta e oitenta do século passado culminaram no avançado alargamento do conceito de patrimônio cultural trazido pelo artigo 216 da Carta Republicana. Dessa forma, fez-se necessário regulamentar os institutos jurídicos de proteção da dimensão imaterial do patrimônio cultural previstos no $\S 1^{\circ}$ do mencionado dispositivo, dentre elas o Registro, e criar novas formas de acautelamento e preservação distintas do já bastante utilizado tombamento.

Assim, em novembro de 1997, quase uma década depois de promulgada a Constituição Federal, na ocasião de um seminário comemorativo dos sessenta anos de funcionamento do Iphan realizado na capital cearense, foi confeccionado um documento denominado Carta de Fortaleza, o qual recomendava, urgentemente, estudos para a criação do registro como forma de proteção do patrimônio cultural imaterial (BRASIL, 2000, p.12). 
O Ministério da Cultura acatou a recomendação dos signatários da Carta de Fortaleza e instituiu, através da Portaria n 37/98, uma comissão assessorada por um grupo de trabalho, "com a finalidade de elaborar proposta visando o estabelecimento de critérios, normas e formas de acautelamento do patrimônio imaterial brasileiro" (11).

Após várias reuniões e colaborações de especialistas, chegou-se à versão final do Decreto 3551/2000 que é o instrumento normativo base desse estudo.

Lévi-Strauss, na qualidade de representante da Unesco, participou do seminário que elaborou a Carta de Fortaleza, contribuindo também com algumas sugestões na confecção do Decreto 3551/2000. Este militante cultural francês sintetiza bem o trabalho empreendido na criação do Decreto que regulamentou o registro, in verbis:

\footnotetext{
"O novo decreto sobre bens culturais imateriais do Brasil e o programa nacional para sua salvaguarda respondem, por conseguinte, às prioridades da UNESCO, mas são também notáveis por vários outros fatores. De início, pela rapidez e seriedade com que o decreto foi preparado. Resultante da Carta de Fortaleza, adotada em novembro de 1997 como recomendação de um seminário internacional de alto nível, os trabalhos que o fundamentaram se desenrolaram em menos de três anos, graças às orientações estabelecidas pela comissão criada em março de 1998, [...] mas também graças ao dinamismo incansável do grupo de trabalho [...]." (LÉVI-STRAUSS, 2001, p.26).
}

Dessa forma, vê-se que o instituto do registro, regulamentado através do Decreto 3551/2000, foi criado em consonância com as diretrizes da Unesco, dentro das discussões do contexto internacional, sendo, ainda, discutido e pensado pelos intelectuais da cultura brasileira.

\subsection{Conceito}

A doutrina jurídica acerca do instituto do registro é lacunosa, com raras exceções. Talvez porque o Decreto que o regulamentou tenha somente seis anos, ou então a doutrina especializada concentrou seus estudos no tombamento e desapropriação.

Humberto Cunha Filho afirma que o registro é 
"[...] uma perenização simbólica dos bens culturais. Esta perenização dá-se por diferentes meios os quais possibilitam às futuras gerações o conhecimento dos diversos estágios porque passou o bem cultural." (CUNHA FILHO, 2000, p.125).

Através desse conceito formulado antes mesmo da elaboração do Decreto, vê-se a preocupação do autor em perenizar sem impedir a evolução dos estágios do bem cultural. É o registro histórico sem atrapalhar a dinâmica do bem imaterial.

Anos após, José Afonso da Silva, não sem explícita desatualização, sustenta que "o registro e o inventário não são formas regulamentadas" e, em manifestação algo contraditória, logo em seguida arrola o conjunto de registros para efeitos de proteção autoral, definidos essencialmente na Lei $n^{\circ}$ 9.610/1998, como sendo "uma forma de conservação" (2006, p.811).

No intuito de fortalecer uma doutrina jurídica acerca dos direitos culturais, formulase, nesse estudo, um conceito de que registro é uma ação do Poder Público com a finalidade de identificar, reconhecer e valorizar as manifestações culturais e os lugares onde estas se realizam, os saberes e as formas de expressões dos diferentes grupos formadores da sociedade brasileira, levando-se em consideração o binômio mutação-continuidade histórica do patrimônio cultural imaterial.

\subsection{Finalidade}

Uma das grandes indagações a serem feitas neste trabalho é acerca da finalidade do registro. Para que serve realmente este instrumento previsto na Carta Magna e regulamentado pelo Decreto 3551/2000?

Lévi-Strauss avalia a intenção do Decreto da seguinte maneira:

"O decreto propõe, sobretudo, uma solução inovadora do problema que parecia a priori insuperável, de integrar, num mesmo dispositivo, a prodigiosa diversidade e a infinidade de aspectos das inúmeras criações culturais reunidas na denominação genérica e cômoda, mas certamente simplificadora, de patrimônio imaterial [...]." (LÉVI-STRAUSS, 2001, p.26, grifo do autor). 
Mais adiante, Lévi-Strauss procura explicar a impossibilidade de se proteger mais incisivamente o patrimônio cultural imaterial, uma vez que este possui natureza intrinsecamente mutante:

"Gostos, necessidades, modos de vida, valores e representações sempre evoluíram e continuarão a fazê-lo e, se uma comunidade abandona uma prática social, não há como se opor. O que pode ser feito, e o decreto atende a isto, é, por um lado, inventariar, estudar e conservar e, por outro, oferecer reconhecimento social aos detentores desse patrimônio para que tenham reconhecida sua importância, convidando-os a perpetuá-lo a transmiti-lo às novas gerações que, por sua vez, terão tomado consciência de seu valor." (LÉVISTRAUSS, 2001, p.27).

É verdade que os bens imateriais são dinâmicos, sendo necessária uma mínima intervenção possível. Contudo, entende-se, neste trabalho, principalmente com relação aos bens imateriais relacionados aos saberes, que o argumento de que não se deve (ou não se pode) protegê-los em virtude de sua dinâmica natural constitui uma falsa premissa. É possível, sim, proteger os bens imateriais contra os abusos e apropriações cometidas à propriedade intelectual coletiva dos detentores / produtores dos bens imateriais. Alegar que não é correto proteger os bens imateriais, devendo somente identificá-los e reconhecê-los, é abaixar a guarda.

Através de uma análise do próprio $\$ 1^{\circ}$ do art. 216 da Lei Maior, infere-se, à primeira vista, que o registro é uma forma exemplificativa de proteção ou até mesmo de acautelamento e preservação do patrimônio cultural imaterial.

Contudo, ao se fazer uma análise minuciosa desse instituto, verifica-se que o Decreto que o regulamentou não transformou o registro em um instrumento de proteção conforme está disposto na Lei das Leis, mas tão somente em uma ferramenta de identificação, guardando poder bastante limitado para se proteger o patrimônio cultural imaterial.

$\mathrm{Na}$ verdade, o registro, em si, não é satisfativo, ou seja, necessita de outros instrumentos de salvaguarda para proteger o patrimônio cultural imaterial eficazmente. Isso é ocasionado, principalmente, pela inexistência no Decreto de 
restrições à propriedade intelectual, principalmente ao registro de saberes, que seria o modo mais contundente de proteção, tal como ocorre com o tombamento.

Na ocasião da elaboração do Decreto 3551/2000, os intelectuais envolvidos em sua criação alegaram que os debates acerca da propriedade intelectual eram embrionários e que, à época da confecção do mencionado instrumento normativo, era necessário, em um primeiro plano, identificar precisamente os bens culturais imateriais e, somente após, se estabelecer instrumentos de proteção dos mesmos.

É o que se extrai do Relatório Final das Atividades da Comissão e do Grupo de Trabalho Patrimônio Imaterial, o qual deixa clara a opção pela não inclusão de instrumentos de proteção da propriedade intelectual, apesar de por demais debatida:

"[...] diante do atual estágio da discussão internacional e da necessidade de maior aprofundamento do tema (proteção da propriedade intelectual) junto a outras instâncias governamentais, seria precipitado e inadequado dispor sobre o assunto no momento. Avaliou-se que seria mais importante iniciar um trabalho de identificação, inventário, registro e reconhecimento do patrimônio imaterial de relevância nacional, para, num segundo momento, se estabelecer dispositivos de proteção para equacionar questões específicas que o uso e a comercialização desses produtos envolve." (BRASIL, 2000, p.15).

Apesar de muitas moções em favor da inclusão de normas relativas à proteção da propriedade coletiva no registro, os elaboradores do Decreto 3551/2000 acharam o tema pouco explorado e inoportuno, deixando de criar, dessa forma, um instrumento de vanguarda. Na verdade, faltou o destemor que a geração dos modernistas tiveram à elaboração do Decreto 25/37.

Até hoje não foi resolvido esse impasse. Márcia Sant'Anna demonstra a preocupação atual com as questões relativas à proteção da propriedade intelectual coletiva, ipsis litteris:

\footnotetext{
"A defesa de direitos vinculados ao uso de conhecimento tradicionais ou à reprodução / difusão de padrões ou de imagens relacionadas a expressões culturais tradicionais é, em todo mundo, um campo que necessita ainda ser desenvolvido, tanto em termos conceituais quanto no que toca a criação de instrumentos de proteção. Embora instrumentos jurídicos
} 
destinados ao reconhecimento e ao exercício de direitos coletivos e difusos sejam ainda escassos e, muitas vezes, inadequados, a salvaguarda de bens culturais imateriais não os pode ignorar e muito menos passar ao largo dessas questões." (SANT'ANNA, 2005, p.8).

Compartilha-se a preocupação da arquiteta, porém, entende-se que a pesquisa em busca de um novo instrumento para salvaguardar a propriedade intelectual coletiva deva ser elaborada a partir da comunidade cultural, e não de instituições da sociedade internacional vinculadas a interesses econômicos e comerciais, como sói acontecer.

\subsection{Efeitos}

O registro, como já dito anteriormente, não possui qualquer constrição ao direito de propriedade intelectual; tampouco produz obrigações aos sujeitos envolvidos com o bem registrado. Entretanto, principalmente ao Estado, destacam-se alguns efeitos advindos do registro.

São eles: a obrigação pública de documentar e acompanhar a dinâmica das manifestações culturais registradas; o reconhecimento da importância do bem e valorização mediante o título de Patrimônio Cultural do Brasil; e ações de apoio, no âmbito do Programa Nacional de Proteção do Patrimônio Imaterial.

Márcia Sant'Anna explicita esse papel do Estado:

\footnotetext{
"O registro institui o reconhecimento de que essas expressões vivas da cultura também integram o patrimônio cultural brasileiro e estabelece, para o Estado, o compromisso de salvaguardá-las por meio de documentação, acompanhamento e apoio às suas condições de existência. É ainda, e principalmente, um instrumento de preservação adaptado à natureza dinâmica dessas manifestações [...]." (SANT'ANNA, 2005, p.7).
}

Vê-se, portanto, que o registro não é auto-suficiente para proteger um bem imaterial, necessitando sempre do auxílio de outros meios para a guarida real desse bem intangível. Muitos desses auxílios aparecerão no Programa Nacional de Proteção do Patrimônio Imaterial com a importante missão de complementar o registro. 


\subsection{Da adequação do Decreto Presidencial para regulamentação do registro}

O registro, cuja previsão constitucional consta no $\S 1^{\circ}$ do art. 216 , foi regulamentado através de um decreto presidencial. Indaga-se, a partir disso, se este simples decreto é a forma mais adequada para a regulamentação desse instituto; e se esta é a forma legislativa mais adequada para a regulamentação desse instituto, uma vez consideradas a instabilidade e fragilidade normativa do instrumento.

Conforme já visto no tópico 3.3 deste estudo, não era de interesse de alguns intelectuais, à época da elaboração dos estudos para criação do registro, a inclusão de restrições ao direito de propriedade intelectual. Tal omissão pode ser explicada também através da intenção de conferir maior rapidez à criação do registro, considerando que se houvesse tal inclusão de restrições à propriedade intelectual, o registro teria, necessariamente, que ser instituído através de lei, em consonância com 0 art. $5^{\circ}$, II da Constituição Federal, o que demandaria, sem dúvida, uma dificuldade maior na criação de tal norma.

O registro, dessa forma, tornou-se um instrumento de aceitação quase unânime, uma vez que não auferia ônus a ninguém, a não ser aos órgãos competentes de cultura.

Vale aqui transcrever trecho do memorando da então procuradora jurídica-chefe do Iphan, Sista Souza dos Santos, que esclarece os motivos da adequação do decreto como forma legislativa para se criar o registro, ipsis litteris:

"O art. 216 da Constituição Federal não se reveste de auto-executoriedade. Desta feita, o ideal seria que esse dispositivo constitucional fosse regulamentado por lei. Contudo, sabese das dificuldades enfrentadas para que um projeto de lei venha a ser aprovado, cuja tramitação é sempre árdua e vagarosa. Então, considerando-se que não existirão maiores obrigações para o detentor do objeto caracterizado como patrimônio imaterial, e segundo o preceito constitucional inserto no art. $5^{\circ}$, inciso II, pelo qual 'Art. $5^{\circ}$ - Todos são iguais perante a lei, sem distinção de qualquer natureza, garantindo-se aos brasileiros e aos estrangeiros residentes no País a inviolabilidade do direito à vida, à liberdade, à igualdade, segurança e à propriedade, nos seguintes termos:...II - ninguém será obrigado a fazer ou deixar de fazer alguma coisa, senão em virtude de lei' é tolerável 
que a regulamentação da matéria se faça por meio de Decreto Presidencial." (BRASIL, 2000 , p. 175, grifo do autor).

Conclui-se que a inexistência de normas referentes à propriedade intelectual no Decreto 3551/2000, mormente ao registro dos saberes, deu-se em nome da viabilidade e rapidez da criação do próprio registro, mesmo que isso implicasse a completa ineficácia de tal instrumento como forma de proteção do patrimônio cultural imaterial. Portanto, o Decreto Presidencial, nos moldes como foi idealizado o registro, é, sim, a forma mais adequada, porém pouco ousada.

\section{Processo de registro}

Neste capítulo, analisa-se, pormenorizadamente, todo o procedimento administrativo descrito no Decreto 3551/2000, visando ao registro de um bem imaterial.

\subsection{Partes legítimas para provocar a instauração do processo de registro}

O art. $2^{\circ}$ do Decreto $3551 / 2000$ esclarece quais partes são legítimas para provocar a instauração do processo de registro. Estas são: o Ministro de Estado da Cultura; as instituições vinculadas ao Ministério da Cultura (12); as Secretarias de Estado, de Município e do Distrito Federal; e, por fim, as sociedades ou associações civis.

Durante os debates acerca da versão final do art. $2^{\circ}$ do referido Decreto Presidencial, discutiu-se bastante quais partes estariam legitimadas para propor a instauração do processo de registro.

Cogitou-se, à época, a possibilidade de qualquer cidadão possuir legitimidade para provocar a instauração do processo de registro, o que foi duramente atacado por Joaquim Falcão (BRASIL, 2000, p.112) que considerava que tal atitude sobrecarregaria o Conselho Consultivo do Patrimônio Cultural "com enxurrada de propostas locais e de pouca importância", considerando, ainda, que "entidades de expressão nacional ou regional (13) estarão aptas a encaminhar propostas para o registro de bens de relevância nacional".

Entende-se que tal pensamento limita o princípio da participação popular em nome de uma hipotética desburocratização. Ademais, a provocação da instauração do 
processo de registro através das entidades, em detrimento da participação direta do cidadão, não significa dizer uma melhor instauração.

O que se verifica atualmente é a ínfima quantidade de provocações que se concretizam, ou seja, poucos bens registrados (14). Infere-se, portanto, duas hipóteses: ou as entidades não estão provocando a instauração dos processos em quantidades satisfatórias ou estão fazendo-a de maneira tecnicamente equivocada, de modo que esbarram na burocracia instrutória prevista na resolução 001/2006 do Conselho Consultivo do Patrimônio Cultural (15).

\subsection{O Conselho Consultivo do Patrimônio Cultural}

O Conselho Consultivo do Patrimônio Cultural é o órgão responsável pelo registro dos bens imateriais, conforme descrito no Decreto 3551/2000. Este Conselho integra o Iphan, sendo presidido, necessariamente, pelo presidente desta entidade.

É bem verdade que a escolha do Conselho Consultivo do Patrimônio Cultural para processar o registro foi uma decisão corporativa, uma vez que se sondava, à época da formulação do Decreto 3551/2000, criar um órgão específico para tal, o que foi de logo rejeitada, no intuito de prestigiar o Iphan (BRASIL, 2000, p.35).

O Conselho é composto por dezoito representantes da sociedade civil e um membro das seguintes instituições: Ibama - Instituto Brasileiro do Meio Ambiente e dos Recursos Naturais Renováveis; IAB - Instituto de Arquitetos do Brasil; Icomos International Council on Monuments and Sites e Museu Nacional.

Tal Colegiado recebe auxílio substancial de dois órgãos: a Câmara do Patrimônio Imaterial do Conselho Consultivo do Patrimônio Cultural e a Gerência de Registro do Departamento do Patrimônio Imaterial. Estes setores é que organizam o processo de registro, inclusive no que concerne à instauração e à instrução dos processos que são submetidos à deliberação final do Conselho Consultivo, veja-se:

"A Gerência de Registro do Departamento do Patrimônio Imaterial, em conjunto com a Câmara do Patrimônio Imaterial do Conselho Consultivo do Patrimônio Cultural, é a unidade responsável pela tramitação administrativa e construção de entendimentos relativos aos 
processos de registro. Isso significa, de início, ser responsável pelo recebimento e avaliação preliminar das propostas de Registro de bens culturais de natureza imaterial que são encaminhadas ao IPHAN. [...] A Gerência acompanha os processos abertos em decorrência dessas propostas, bem como orienta e supervisiona sua instrução técnica. Por fim, avalia ou formula diretamente pareceres técnicos sobre a pertinência do Registro requerido e sobre a qualidade da instrução técnica realizada, os quais subsidiam a decisão final do Conselho Consultivo do Patrimônio Cultural sobre o assunto." (BRASIL, 2005, p.26).

É o Conselho Consultivo do Patrimônio Cultural, portanto, instância máxima do Iphan que delibera pelo registro de um bem imaterial, auferindo-lhe o título de patrimônio cultural brasileiro.

\subsection{Requisitos para instauração do processo de registro}

Os bens a serem registrados devem necessariamente obedecer a requisitos formais e materiais. Estes dizem respeito aos bens culturais em si, enquanto aqueles concernem, basicamente, à documentação e às questões procedimentais necessárias à obtenção do registro do bem cultural.

\subsubsection{Requisitos materiais}

Os requisitos materiais para instauração do registro são dois: continuidade histórica e relevância nacional.

Ambos estão previstos no $\S 2^{\circ}$ do art. $1^{\circ}$ do Decreto $3551 / 2000$, o qual versa que "a inscrição num dos livros de registro terá sempre como referência a continuidade histórica do bem e sua relevância nacional para a memória, a identidade e a formação da sociedade brasileira" (grifo nosso).

\subsubsection{Continuidade histórica}

A continuidade histórica trata-se de uma contraposição ao conceito de autenticidade bastante utilizado no campo preservacionista (BRASIL, 2000, p.16). É através desta que se averiguará se um bem preenche os requisitos para ser registrado como patrimônio cultural imaterial brasileiro ou se constitui apenas como um fato isolado, desprovido de continuidade histórica. 
Esse requisito influenciou o instituto da revalidação, o qual manterá o título de patrimônio cultural brasileiro somente aos bens culturais que comprovarem sua continuidade histórica, conforme prescreve o art. $7^{\circ}$ do Decreto 3551/2000, aqui transcrito:

\footnotetext{
"Artigo $7^{\circ}$ - O IPHAN fará a reavaliação dos bens culturais registrados, pelo menos a cada dez anos, e a encaminhará ao Conselho Consultivo do Patrimônio Cultural para decidir sobre a revalidação do título de 'Patrimônio Cultural do Brasil'.
}

Parágrafo único. Negada a revalidação, será mantido apenas o registro, como referência cultural de seu tempo."

Como exemplo da aplicabilidade do requisito da continuidade histórica, cita-se o Frevo de Pernambuco (16). Esta dança, que tem início em meados do século 19, em Pernambuco, é, até hoje, executada em todo o Brasil, especialmente no período momino. Tárik de Souza (on line, grifo do autor) descreve a origem e a evolução histórica dessa dança que faz parte do patrimônio cultural brasileiro:

\footnotetext{
"Derivado da polca marcial, inicialmente chamado 'marcha nortista' ou 'marcha pernambucana', o frevo dos primórdios trazia capoeiristas à frente do cortejo. Das gingas e rasteiras que eles usavam para abrir caminho teria nascido o passo, que também lembra as czardas russas. Até as sombrinhas coloridas seriam uma estilização das utilizadas inicialmente como armas de defesa dos passistas. De instrumental, o gênero ganhou letra no frevo canção e saiu do âmbito pernambucano para tomar o país."
}

O Frevo, sem dúvida, é uma excelente demonstração de continuidade histórica inclusive com as mutações inerentes aos processos dinâmicos que envolvem os bens imateriais - uma vez que, mesmo atravessando gerações, permaneceu com o significado cultural inabalável.

\subsubsection{Relevância nacional}

A relevância nacional também está expressa no $\S 2^{\circ}$ do Decreto $3551 / 2000$, que prevê "a inscrição num dos livros de registro terá sempre como referência [...] sua relevância nacional para a memória, a identidade e a formação da sociedade brasileira". 
O próprio entendimento de relevância nacional é bastante complexo, porquanto demasiado subjetivo. O que pode ser relevante para alguns pode não sê-lo para outros. No entanto, ao contrário do que se possa inferir, tal dispositivo não quer dizer que o registro só albergará os bens culturais que forem de conhecimento nacional ou que façam parte da cultura de toda a sociedade brasileira.

Primeiramente, critica-se a impropriedade do termo sociedade brasileira utilizado no Decreto 3551/2000. O presidente da república deveria ter utilizado a expressão prevista no caput do art. 216 da Constituição Federal de 1988, qual seja diferentes grupos formadores da sociedade brasileira, auferindo, assim, uma plasticidade democrática à cultura nacional.

Tal requisito material se trata, na verdade, de uma priorização da concessão do título de patrimônio cultural brasileiro àqueles bens imateriais que possuam referência à memória, à identificação e formação dos diferentes grupos formadores da sociedade brasileira. Em nada tem a ver com a extensão territorial ou popularidade nacional do bem, mas, sim, de seu peso, em si, aos grupos formadores da sociedade brasileira.

Entende-se, neste trabalho, que tal princípio estimula a repartição de competências com outros entes federativos, visando a criação de seus próprios instrumentos de identificação do patrimônio cultural imaterial, permitindo, assim, adequar e organizar políticas públicas culturais locais à proteção do bem registrado.

Assim, ao se registrar bens de relevância nacional, cria-se a oportunidade dos Estados registrarem bens culturais imateriais de relevância estadual, os Municípios fazerem o mesmo com relação aos bens locais, desde que este entes, por suposto, possuam mecanismos para tal fim. No Ceará, existe a lei $n^{\circ} 13.427 / 2003$ que possui tal mister. Inexiste, contudo, legislação análoga no Município de Fortaleza, apesar de ser tal ente federativo competente para legislar sobre proteção do patrimônio cultural de interesse local (17).

\subsubsection{Requisitos formais}


Os requisitos formais são aqueles necessários à instauração e à instrução do processo de registro. $O \S 2^{\circ}$ do art. $3^{\circ}$ do Decreto 3551/2000 prescreve que tal instrução "constará de descrição pormenorizada do bem a ser registrado, acompanhada de documentação correspondente, e deverá mencionar todos os elementos que Ihe sejam culturalmente relevantes".

Tais requisitos estão dispostos na resolução 001/2006, aprovada pelo Conselho Consultivo do Patrimônio Cultural, em sua $49^{a}$ reunião, resumindo toda a praxis administrativa e documentação e informações necessárias à instrução. Ressalte-se, porém, que tal resolução ainda não foi publicada, servindo, neste trabalho, apenas como referência documental.

Preenchidos todos esses requisitos, encaminha-se a proposta de registro ao presidente do Iphan para dar início ao processo de registro.

\subsection{Livros de registro}

Os bens imateriais a serem albergados pelo instituto do registro são inscritos após o cumprimento do procedimento administrativo descrito no Decreto 3551/2000 e na Resolução 001/2006 (18), em um dos quatro livros especiais existentes.

$O \S 1^{\circ}$ do art. $1^{\circ}$ do mencionado Decreto especificou os livros em que os bens imateriais devem ser anotados. São eles: o livro de registro de saberes, o livro de registro de celebrações, o livro de registro das formas de expressão e o livro de registro dos lugares. Há, ainda, a previsão de criação de outros livros para inscrição dos bens imateriais que não se encaixem nos quatro livros indicados no mencionado dispositivo.

Passa-se, agora, a tecer alígeras considerações sobre cada um desses tombos, identificando suas peculiaridades e exemplos de bens registrados.

\subsubsection{Livro de registro dos saberes}

O livro do registro dos saberes está disposto no inciso I do $\S 1^{\circ}$ do art. $1^{\circ}$ do Decreto 3551/2000. Neste livro, serão inscritos "os conhecimentos e modos de fazer enraizados no cotidiano das comunidades". 
São exemplos de saberes a culinária típica de uma região ou técnicas de artesanato. Atualmente, estão registrados no livro de saberes os seguintes bens: Ofício das Paneleiras de Goiabeiras e Modo de fazer Viola-de-cocho.

O Ofício das Paneleiras de Goiabeiras foi o primeiro bem registrado, inscrito no livro de registro de saberes em 20/12/2002. O relatório oficial das ações desenvolvidas pelo Departamento de Patrimônio Imaterial em 2005 (BRASIL, 2005, p. 27) dá conta do "crescimento da procura pelas panelas de barro de Goiabeiras, no Espírito Santo, o que tem, inclusive, demandado ações de apoio, por parte do Iphan, no sentido da melhoria da organização comunitária e gerencial do grupo". Atenta-se, contudo, à descaracterização que tal bem imaterial está suscetível, em virtude da desobediência do princípio da mínima intervenção sobre os bens registrados.

O Modo de fazer Viola-de-cocho foi inscrito no livro de registro de saberes em 14/01/2005. Fato bastante inusitado ocorreu envolvendo o Estado do Mato do Grosso e o Estado do Mato Grosso do Sul com relação a este bem registrado, o qual está relatado oficialmente pelo Iphan, veja-se:

\footnotetext{
"Há o entendimento do Registro como um instrumento de certificação de origem ou semelhante à patente ou ao registro de marcas e obras. O entendimento equivocado de que o instrumento daria aos produtores/detentores de um determinado território o direito de uso exclusivo da denominação do bem, foi o que levou a Secretaria de Cultura do Estado do Mato Grosso a acolher o requerimento de uma associação de violeiros e solicitar ao Conselho Consultivo do Patrimônio Cultural a exclusão do Estado de Mato Grosso do Sul do Registro da Viola de Cocho. O pedido foi examinado e negado pelo Conselho, em $11 / 08 / 2005$, pois o Registro, como instrumento que valoriza expressões culturais pela via do fortalecimento do seu papel na vida social e econômica contemporânea, destina-se a incluir e não a excluir territórios e praticantes. O entendimento do dispositivo, como uma certificação de origem, é o que tem também animado o encaminhamento de alguns pedidos de Registro de receitas culinárias." (BRASIL, 2005, p.28).
}

Márcia Sant'Anna esclarece o impasse da questão referente à propriedade intelectual coletiva dos saberes: 


\begin{abstract}
"O problema da defesa de direitos relacionados à propriedade coletiva de conhecimentos, padrões e técnicas tradicionais vem sendo discutido em nível internacional de modo sistemático há, pelo menos, 10 anos, tendo como principais fóruns a Organização Mundial de Propriedade Intelectual - OMPI e a UNESCO. Contudo, uma vez que o tema, especialmente no plano internacional, envolve interesses econômicos e acordos comerciais importantes entre países, até o momento não se chegou ao consenso sobre como tratar essa questão - se por meio da adaptação de instrumentos do sistema existente de proteção à propriedade intelectual ou se mediante a criação de um sistema jurídico sui generis, adaptado às características desses bens culturais e baseado no conceito de propriedade intelectual coletiva." (SANT'ANNA, 2005, p.13, grifo do autor).
\end{abstract}

Entende-se, neste estudo, que o livro do registro dos saberes poderia guardar uma melhor proteção. Pelo menos com relação aos saberes, deveria haver previsão no Decreto $3551 / 2000$ de formas mais eficazes de proteção da propriedade intelectual coletiva.

Como exemplo de instrumento eficaz, cita-se a apelation controlée da França, não obstante seja conferido pelo Ministério da Agricultura, confere ao bem protegido um selo de qualidade cultural, atestando que tal bem cultural é o autêntico de uma comunidade, ou seja, uma certificação de origem. É o exemplo do champagne, que tem a propriedade intelectual protegida, fazendo com que outros vinhos e espumantes possam ser criados, mas só aqueles feitos na região de Champagne, na França, poderão ser assim denominados.

Isso evitaria constrangimentos, inclusive diplomáticos, acerca da apropriação de saberes de certas comunidades, como aconteceu recentemente com o açaí e com a rapadura, além de proteger o patrimônio cultural imaterial dessas populações de forma mais precisa (19).

\title{
4.4.2 Livro de registro das celebrações
}

O segundo livro que aparece no $\S 1^{\circ}$, II do art. $1^{\circ}$ do Decreto 3551/2000 é o livro de registro das celebrações. É nele que são inscritos "os rituais e festas que marcam a vivência coletiva do trabalho, da religiosidade, do entretenimento e de outras práticas da vida social". 
Há somente um bem registrado nesse livro, qual seja o Círio de Nossa Senhora de Nazaré, o qual foi inscrito em 5/10/2004 (20).

O termo celebrações foi utilizado corretamente, uma vez que se podem incluir nesse livro as manifestações religiosas que integram o patrimônio cultural imaterial e que não poderiam se enquadrar em termos considerados "profanos" como, por exemplo, "livro das festas".

\subsubsection{Livro de registro das formas de expressão}

O livro de registro das formas de expressão, previsto no inciso III do $\S 1^{\circ}$ do art. $1^{\circ}$, é "onde serão inscritas manifestações literárias, musicais, plásticas, cênicas e lúdicas."

Os seguintes bens estão inscritos nesse Livro: Kusiwa - pintura corporal e arte gráfica Wajãpi, do Amapá, inscrito em 20/12/2002; Samba de Roda do Recôncavo Baiano (21), inscrito em 5/10/2004; e, por fim, Jongo no sudeste, inscrito em $15 / 12 / 2005(22)$.

\subsubsection{Livro de registro dos lugares}

O livro de registro de lugares é o quarto e último livro constante no $\S 1^{\circ}$ do $\operatorname{art.~} 1^{\circ}$ do Decreto 3551/2000. São inscritos nesse livro os "mercados, feiras, santuários, praças e demais espaços onde se concentram e reproduzem práticas culturais coletivas".

Segundo Antônio Arantes (BRASIL, 2000, p.165) o termo lugares é o conceito que na teoria social e na geografia melhor descreve a apropriação do espaço físico pelos grupos humanos, o qual foi acertadamente empregado no Decreto 3551/2000.

O Mercado Ver-o-Peso, em Belém, e o Terreiro da Casa Branca, na Bahia, influenciaram a criação do livro dos lugares, considerando que o tombamento de tais lugares sempre foi visto como uma forma inadequada de proteção.

Atualmente, existe um bem registrado no livro de lugares, qual seja a Feira de Caruaru, em Pernambuco, não obstante a Cachoeira de lauaretê - lugar sagrado dos 
povos indígenas dos rios Uaupés e Papuri - também esteja na iminência de ser resgitrado.

\subsubsection{Outros livros}

Há a possibilidade, devido ao processo dinâmico e à mutação que envolve o próprio patrimônio cultural imaterial, de um bem cultural imaterial não se enquadrar em nenhum dos livros mencionados no $\$ 1^{\circ}$ do art. $1^{\circ}$ do Decreto $3551 / 2000$.

Para tanto, o $\S 3^{\circ}$ do mencionado dispositivo (art. $1^{\circ}$ do Decreto $3551 / 2000$ ) previu que

"[...] outros livros de registro poderão ser abertos para a inscrição de bens culturais de natureza imaterial que constituam patrimônio cultural brasileiro e não se enquadrem nos livros definidos no parágrafo primeiro deste artigo."

O parágrafo único do art. $5^{\circ}$ desse Decreto incumbe ao Conselho Consultivo do Patrimônio Cultural proceder a abertura, se necessário, de novo livro de registro (23), visando abarcar, ao máximo, as manifestações que não podem ser inscritas adequadamente nos quatro livros dispostos no art. $1^{\circ}$. É necessário, contudo, uma especificação das categorias correspondentes e uma justificativa a ser exarada pelo órgão competente pela abertura do novel tombo, consoante determina o artigo 15 da Resolução nº 001/2006.

\section{Conclusão}

Podem ser extraídas várias conclusões deste trabalho. Destacam-se, entretanto, duas: uma do ponto de vista epistemológico e outra de um viés mais pragmático.

A primeira, de cunho epistemológico, é a necessidade de se solidificar uma doutrina acerca dos direitos culturais, visando atrair para as Ciências Jurídicas os estudos sobre patrimônio cultural, os quais são investigados, tradicionalmente, por outras ciências - antropologia, culturologia, arquitetura etc. - sem olvidar, é claro, a indispensável interdisciplinaridade. 
Além disso, mesmo logrando êxito ao trazer tais estudos à seara das Ciências Jurídicas, é necessário investigar o patrimônio cultural sobre o prisma dos direitos culturais, descentralizando, dessa forma, o foco exclusivamente ambiental que lhe é dado atualmente.

A de cunho pragmático-jurídica é a principal conclusão deste trabalho. Vislumbrouse ao longo da pesquisa a necessidade de criação de um novo instrumento de proteção do patrimônio cultural imaterial que assegure uma efetiva proteção à propriedade coletiva dos saberes. Viu-se que o registro é um instrumento que assegura uma valorização e um reconhecimento ao bem cultural imaterial, mas não aufere uma proteção real a alguns bens, em especial os saberes, uma vez que não protege a propriedade intelectual coletiva dos detentores de tais bens.

Constatou-se, ainda, a eficácia reduzida do registro como forma de proteção do patrimônio cultural imaterial, considerando que, quase sempre, necessita de outros instrumentos - principalmente os de salvaguarda - para se proteger o bem imaterial agraciado com o título de patrimônio cultural brasileiro.

Urge, portanto, a criação de um novel instrumento de proteção da dimensão imaterial do patrimônio cultural que resguarde, dentre outras coisas, a propriedade intelectual coletiva e seja, quanto ao seu alcance, auto-suficiente na missão de proteger.

\section{Notas}

(1) Art. 215. O Estado garantirá a todos o pleno exercício dos direitos culturais e acesso às fontes da cultura nacional, e apoiará e incentivará a valorização e a difusão das manifestações culturais.

(2) Como exemplo, cita-se o art. 179, XXXIII da Constituição de 1824, o qual previa que "Collegios, e Universidades, aonde serão ensinados os elementos das Sciencias, Bellas Letras, e Artes."

(3) Miguel Reale e seu culturalismo jurídico; no âmbito da Sociologia do Direito, A. L. Machado Neto; e, recentemente, o constitucionalista José Afonso da Silva, ao identificar os direitos culturais; a ambientalista Lúcia Reisewitz, ao auferir uma visão ambientalista aos direitos culturais; e, por fim, o doutrinador Francisco Humberto Cunha Filho, ao criar um sistema autônomo dos ditos direitos, como um novo ramo da Ciência Jurídica. 
(4) Os quais muitas vezes carregam o estigma de sui generis, como exemplo: o direito autoral, no direito civil e o tombamento, no direito administrativo.

(5) A Carta Internacional sobre Conservação e Restauração de Monumentos e Sítios, conhecida como Carta de Veneza, extraída na ocasião do Segundo Congresso Internacional de Arquitetos e Técnicos dos Monumentos Históricos, em maio de 1964, é considerado o primeiro documento internacional a auferir importância ao significado cultural de patrimônio cultural. Além disso, a Recomendação sobre a Salvaguarda da Cultura Tradicional e Popular, criada na $25^{\text {a }}$ Conferência Geral da Unesco, realizada em Paris, em 15 de novembro de 1989, fazendo frente ao conceito essencialmente materialista de patrimônio cultural inserto na Convenção da Unesco sobre a Proteção do Patrimônio Mundial, Cultural e Natural de 1972, é considerado o marco inicial à proteção do patrimônio cultural imaterial no mundo ocidental, e, mais recentemente, a Convenção para a Salvaguarda do Patrimônio Cultural Imaterial de 2003, consolidando o conceito de patrimônio cultural imaterial.

(6) Principalmente os debates coordenados por Aloísio Magalhães, resgatando o visionário estudo de Mário de Andrade.

(7) "Localizadas na Capela de São José, na cidade Canguaretama. O conjunto de dezesseis imagens representando a morte de Nossa Senhora, se distingue como um dos melhores exemplares da imaginária sacra, segundo Oswaldo Câmara de Souza. Possivelmente esculpidas em fins do século XVII ou princípio do XVIII, as imagens representam: a dor das três Marias (27 e $28 \mathrm{~cm}$ ), São Judas, São Pedro, São Felipe, São Bartolomeu, São Simão, São Thomé, São Thiago, São Matias, São João, São Mateus, Santo André, São Tiago, cujas medidas variam de 25 a $30 \mathrm{cms}$. Esculpidas em madeira, não possuem olhos de vidro e permanecem com a pintura primitiva, bem como laimadas a ouro e estofadas com apuro, segundo Oswaldo C. de Souza". Informações obtidas em: <http://www2.iphan.gov.br/ans/inicial.htm>. Acesso em3 nov. 2006.

(8) Para se inventariar a dimensão imaterial do patrimônio cultural é utilizado o Inventário Nacional de Referências Culturais fomentado através do Plano Nacional do Patrimônio Imaterial do Iphan.

(9) O decreto-lei n ${ }^{\circ} 25 / 37$, que regulamenta o tombamento, por sua vez, foi recepcionado pela Carta Magna.

(10) No mundo oriental, a proteção legal às expressões do patrimônio cultural imaterial remonta à década de 50 , mormente no Japão através da Law for the Proctetion of Cultural Properties. Disponivel em <http://www.tobunken.go.jp/ kokusen/ENGLISH/DATA/Htmlfg/japan/japan01.html>. Acesso em: 21 ago. 2006.

(11) Portaria n 37, de 04 de março de 1998, publicada no Diário Oficial da União, em 6 de março de 1998.

(12) São instituições vinculadas ao MINC: Agência Nacional do Cinema - Ancine, Fundação Biblioteca Nacional, Centro Técnico Audiovisual, Cinemateca Brasileira, Fundação Casa Rui Barbosa, Fundação Cultural Palmares, Fundação Nacional de Arte, Instituto do Patrimônio Histórico Nacional - Iphan e Centro Nacional de Folclore e Cultura Popular.

(13) O texto do Decreto 3551/2000 não especifica, contudo, a abrangência dessas entidades, limitando-se a dizer "sociedade ou associações civis". 
(14) Atualmente, existem 7 bens registrados e 21 processos em andamento, segundo informações disponíveis em: <http://portal.iphan.gov.br/portal/baixaFcdAnexo.do?id=201>. Acesso em: 26 out. 2006.

(15) Resolução aprovada pelo Conselho Consultivo do Patrimônio Cultural em sua 49a reunião,de 3 de agosto de 2006, instituindo os procedimentos a serem observados na instauração e instrução do processo administrativo de Registro de Bens Culturais de Natureza Imaterial. Tal resolução, apesar de aprovada, ainda não foi publicada oficialmente, servindo, neste trabalho, apenas como documento que orienta a práxis administrativa do processo de registro.

(16) Mário de Andrade (apud SOUZA, on line), em seu Dicionário Musical Brasileiro define o frevo como "dança instrumental, marcha em tempo binário e andamento rapidíssimo".

(17) Entendimento contrário: DI PIETRO, Maria Sylvia Zanella. Direito administrativo. 11. ed. São Paulo, Atlas, 1999, p. 130 .

(18) Esta resolução, repita-se, ainda não foi publicada, mas sintetiza o trâmite do processo administrativo de registro.

(19) Sobre o assunto, ver: PAIVA, Ricardo Bacelar. A rapadura e sua proteção legal. Leis e Letras, Fortaleza, Poder Local, n.1, p..48-49, fev. 2006.

(20) Há mais bens que estão em processo de registro. Como exemplo, cita-se o Festival Folclórico de Parintins dos Bois-Bumbás Garantido e Caprichoso, no Amazonas, e os Cantos Sagrados de Milho Verde, em Minas Gerais.

(21) Considerado também pela Unesco como obra prima do patrimônio oral e imaterial da humanidade, título conferido em novembro de 2005.

(22) Ressalte-se, dentre outras formas de expressão, a tramitação do processo de registro da obra de Patativa do Assaré, proposta pelo Instituto de Arquitetos do Brasil - CE. Contudo, acredita-se que é necessário abrir um novo livro para enquadrar a obra de Patativa do Assaré; talvez o livro dos gênios.

(23) A lei 13.427/2003 do Estado do Ceará já prevê a existência do livro dos mestres e do livro dos guardiões da memória, além dos quatro livros já contidos no decreto 3551/2000.

\section{Referências Bibliográficas}

BRASIL. Ministério da Cultura. Patrimônio imaterial: O registro do patrimônio imaterial. Dossiê final das atividades da comissão e do grupo de trabalho patrimônio imaterial. Brasília: Iphan, 2000.

Ministério da Cultura. Relatório de atividade: Departamento do Patrimônio Imaterial. Brasília: Iphan, 
BRUNO, Artur; CUNHA FILHO, Francisco Humberto (organizadores e anotadores). Normas básicas da atividade cultural. Fortaleza: Inesp - Assembléia Legislativa do Estado do Ceará, 1998.

CANOTILHO, José Joaquim Gomes. Direito Constitucional. Coimbra: Almedina, 1991.

CUNHA, Danilo Fontenele Sampaio. Patrimônio cultural: proteção legal e constitucional. Rio de Janeiro: Letra Legal, 2004.

CUNHA FILHO, Francisco Humberto (Org.). Cartilha dos direitos culturais. Fortaleza: Secção Ceará da Ordem dos Advogados do Brasil, 2004.

Francisco Humberto. Cultura e democracia na Constituição Federal de 1988: A representação de interesses e sua aplicação ao programa nacional de apoio à cultura. Rio de Janeiro: Letra legal, 2004.

Direitos culturais como direitos fundamentais no ordenamento jurídico brasileiro. Brasília:

Brasília Jurídica, 2000.

CURY, Isabelle (Org.). Cartas patrimoniais. 2. ed. Rio de Janeiro: Iphan, 2000.

DI PIETRO, Maria Sylvia Zanella . Direito administrativo. 11. ed. São Paulo: Atlas, 1999.

LÉVI-STRAUSS, Laurent. Patrimônio imaterial e diversidade cultural: o novo decreto para a proteção dos bens imateriais. Revista Tempo Brasileiro, Rio de Janeiro, n.147, p. 23-27, out. 2001.

MELLO, Celso Antônio Bandeira de. Curso de direito administrativo. 18. ed. São Paulo: Malheiros, 2004.

PAIVA, Ricardo Bacelar. A rapadura e sua proteção legal. Leis e Letras, Fortaleza, Poder Local, n.1, p. 48-49, fev. 2006.

REISEWITZ, Lúcia. Direito ambiental e patrimônio cultural: direito à preservação da memória, ação e identidade do povo brasileiro. São Paulo: Juarez de Oliveira, 2004.

RODRIGUES, Francisco Luciano Lima. Conceito de patrimônio cultural no Brasil: do Conde de Galvéias à Constituição Federal de 1988. In: MARTINS, Clerton (Org.). Patrimônio cultural: da memória ao sentido de lugar. São Paulo: Roca, 2006. p.9-15.

SANT'ANNA, Márcia. Políticas públicas e salvaguarda do patrimônio cultural imaterial. In: FALCÃO, Andréa (Org.). Registro e políticas públicas de salvaguarda para as culturas populares. Rio de Janeiro: Iphan, 2005. p. 713.

SILVA, José Afonso da. Comentário contextual à Constituição. São Paulo: Malheiros, 2006.

Ordenação constitucional da cultura. São Paulo: Malheiros, 2001. 
SOUZA

Tárik

de.

Frevo.

Disponível

em:

<http://cliquemusic.uol.com.br/br/Generos/Generos.asp?Nu_Materia=10>. Acesso em: 30 out. 2006.

\section{Legislação:}

BRASIL (Império). Constituição Política do Império do Brazil de 1824, de 25 de março de 1824. Disponível em: $<$ http://www.planalto.gov.br>. Acesso em: 27 out. 2006.

República dos Estados Unidos do Brasil. Constituição da República dos Estados Unidos do Brasil de

1934, de 16 de julho de $1934 . \quad$ Disponível em: <http://www.planalto.gov.br/ccivil_03/Constituicao/Constitui\%E7ao34.htm>. Acesso em: 27 out. 2006.

República Federativa do Brasil. Constituição da República Federativa do Brasil: texto promulgado em de 5 de outubro de 1988, com as alterações adotadas pelas emendas constitucionais $\mathrm{n}^{\text {os }} 1 / 92$ a $52 / 2006$. Brasília: Senado, 2006.

Lei $n^{\circ}$ 9.610, de 19 de fevereiro de 1998. Altera, atualiza e consolida a legislação sobre direitos autorais e dá outras providências. Disponível em: <http://www.planalto.gov.br/CCIVIL/Leis/L9610.htm>. Acesso em: 28 out. 2006.

Decreto $n^{\circ} 3.551$, de 2 de outubro de 2000. Institui o registro de bens culturais de natureza imaterial que constituem patrimônio cultural brasileiro, cria o Programa Nacional do Patrimônio Imaterial e dá outras providências. Disponível em: <http://www.iphan.gov.br>. Acesso em: 15 mar. 2006.

Decreto-lei $n^{\circ} 25$, de 30 de novembro de 1937. Organiza a proteção do patrimônio histórico e artístico nacional. Disponível em: <https://www.planalto.gov.br>. Acesso em: 15 mar. 2006.

Portaria $n^{\circ} 37$, de 4 de março de 1998. Instituiu comissão com a finalidade de elaborar proposta, visando ao estabelecimento de critérios, normas e formas de acautelamento do patrimônio imaterial brasileiro. In: Dossiê final das atividades da comissão e do grupo de trabalho patrimônio imaterial. Brasília: Iphan p.45-46, jul. 2000.

CEARÁ, (Estado). Lei no 13.427, de 30 de dezembro de 2003. Institui, no âmbito da administração pública estadual, as formas de registro de bens culturais de natureza imaterial ou intangível que constituem patrimônio cultural. In: BRASIL, Seção Ceará da Ordem dos Advogados do Brasil. Cartilha dos direitos culturais. Fortaleza: [s.n.], 2004. p. 24.

JAPÃO, Law for the proctetion of cultural properties. disponível em <http://www.tobunken.go.jp/ kokusen/ENGLISH/DATA/Htmlfg/japan/japan01.html>. Acesso em: 21 ago. 2006.

\section{Documentos:}

BRASIL. Instituto do Patrimônio Histórico e Artístico Nacional. Conselho Consultivo do Patrimônio Cultural. Resolução $n^{\circ}$ 001, aprovada pelo Conselho em sua 49a reunião, ocorrida em 3 de agosto de 2006. Institui os procedimentos a serem observados na instauração e instrução do processo administrativo de Registro de Bens Culturais de Natureza Imaterial. Trecho disponível em: <www.iphan.gov.br>. Acesso em: 30 out. 2006. 
CARTA de Fortaleza. In: Dossiê final das atividades da comissão e do grupo de trabalho patrimônio imaterial. Brasília: Iphan, jul. 2000. p.33-36.

CARTA de Veneza. In: CURY, Isabelle (Org.). Cartas patrimoniais. 2. ed. Rio de Janeiro: Iphan, 2000.

CONVENÇÃO de Paris. In: CURY, Isabelle (Org.). Cartas patrimoniais. 2. ed. Rio de Janeiro: Iphan, 2000.

RECOMENDAÇÃO sobre a salvaguarda da cultura tradicional e popular. In: CURY, Isabelle (Org.). Cartas patrimoniais. 2. ed. Rio de Janeiro: Iphan, 2000.

UNESCO. Recomendação para a salvaguarda do patrimônio cultural imaterial. Disponível em: <http://www.unesco.org.br/areas/cultura/areastematicas/patrimonio/patrimonioimaterial/index_html/mostra_docu mento>. Acesso em: 30 out. 2006.

* Bacharel em Direito. Membro do grupo de pesquisa em Direitos Culturais da Universidade de Fortaleza - Unifor. 